\title{
Sobre o desenvolvimento do design e da imagem gráfica contemporâneos: a Bauhaus e o estilo suíço
}

Claudia lrene de Quadros Universidade Tuiuti do Paraná / UTP Itanael Bastos de Quadros Jr. Universidade Federal do Paraná / UFPR 


\section{Resumo}

$\mathrm{O}$ artigo aborda o desenvolvimento e a importância da Escola Bauhaus e do Estilo Suíço na comunicação gráfica contemporânea. A Bauhaus, que sonhava com a ordem e a democratização do acesso ao conhecimento, valeu-se de aportes técnicos e conceituais da psicologia, da publicidade e de outras ciências para gerar um novo espaço de expressão e de articulação gráfica. Os experimentos realizados na legendária escola alemã, na primeira metade do século XX, ganharam uma nova perspectiva crítica ao serem recuperados pelo Estilo Suíço. Informar com objetividade, sem a intromissão dos sentimentos subjetivos do designer, passou a ser um dos anseios daqueles que seguiam este estilo. Era o momento de informar mais, de mostrar mais, de dizer mais.

\section{Palavras-chave}

comunicação, design, imagem gráfica, tipografia, Bahaus, estilo suíço

\section{Abstract}

This essay focuses on the development and importance of the Bauhaus School and the Swiss Style within the contemporary graphical communication. The Bauhaus, that dreamed about the order and the democratic access to knowledge, made use of technical and conceptual apparatuses from other areas such as Psychology, Advertising and other Sciences in order to generate a new space for expression and graphic articulation. The experiments held in the legendary German school, in the first half of the twentieth century, have gained a new critical perspective when recovered by the Swiss Style. One of the desires of the followers of the referred style was to inform with objectivity, without the interference of designer subjective emotions. It was the right moment to inform more, to show more and to say more.

\section{Key words}

communication, design, graphic image, typography, Bauhaus, swiss style 


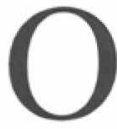

$\mathrm{s}$ expertos discordam sobre as raízes do desenho gráfico. Alguns identificam as pinturas rupestres como exemplos ancestrais dos signos gráficos, outros reconhecem suas formas embrionárias no Egito, Grécia, México e Roma. Vários autores consideram que o desenho gráfico surge junto à invenção dos tipos móveis. Uma corrente aponta as vanguardas artísticas do início do século XX. Outros, ainda, colocam o pensamento contemporâneo com respeito ao desenho gráfico após a Segunda Guerra Mundial, como um fenômeno atrelado ao forte desenvolvimento industrial e dos meios de comunicação de massa.

James Craig e Bruce Barton tentam aclarar as fontes do desenho gráfico:

A história do desenho gráfico é uma infinita fascinação: a magia das primeiras imagens; a beleza dos hieróglifos egípcios, a evolução do alfabeto fonético, a genial invenção de Gutenberg, a acelerada mecanização da composição gráfica e a explosão da imaginação no século vinte. Com uma herança tão fértil, desafortunadamente muitos desenhistas gráficos sabem mais sobre a história da pintura do que sobre a história do desenho gráfico. Uma das razões para esta contradição talvez, seja a crença de que o desenho gráfico é uma inovação do século vinte e que é uma profissão sem história. Isto não é verdade porque o desenho gráfico - ou comunicação visual - começou nos tempos pré-históricos e foi praticado durante séculos por artesãos, escribas, impressores, artistas comerciais e inclusive pintores. (Craig; Barton, 1987, p. 09) 
Definitivamente, é possível admitir que, em um sentido mais amplo, a comunicação visual tem uma história bastante longa. Quando o homem primitivo buscava alimento e encontrava uma pegada de um animal impressa no lodo, na realidade estava recebendo uma mensagem através de um signo gráfico.

Não obstante, apesar da longa trajetória em direção à atualidade da comunicação visual, é possível balizar que o desenho, como atividade moderna, se constituirá como uma demanda da revolução industrial. Herbert Spencer assegura que as raízes da tipografia e do desenho gráfico modernos se entrelaçam com as da pintura, da poesia e da arquitetura do século XX:

O novo vocabulário da tipografia e do desenho gráfico foi amalgamado em menos de vinte anos (...) Com certeza, a tipografia moderna não foi fruto da repentina invenção de um homem, nem sequer de um grupo. Nasceu como una resposta às novas exigências e às novas oportunidades que o século XIX trouxe consigo. A violência com que a tipografia moderna irrompe em cena no comȩ̧o do século $X X$ reflete a agressividade com que os novos conceitos sobre arte e desenho, em cada campo, varreram convenções esgotadas e atacaram atitudes que não tinham relevância numa sociedade altamente industrializada. (Spencer, 1995, p. I1)

Nas principais capitais européias, o desenho gráfico se revela como parte da moderna sociedade industrial. Este desenho gráfico surge, portanto, em cartazes, logotipos, folhetos de publicidade, catálogos de componentes industriais e de feiras. A chamada arte comercial (commercial art) se manifestará no trabalho dos artistas dos cartazes. A comunicação visual, porém, foi estabelecida nos anos 20 pelos artistas de vanguarda.

Os movimentos artísticos mais destacados no final da Primeira Guerra Mundial foram o Expressionismo e o Dadaísmo. Os cartazes que os artistas expressionistas produziram, massivamente, estavam marcados pela ilustração agressiva, cujos contrastes vio- 
lentos se enfrentavam com o letreiro livre ou com o uso de letras pesadas originalmente desenhadas para a publicidade. A ênfase nestas técnicas deixaram algumas peças gráficas notáveis, contudo não imprimiram uma marca duradoura sobre o design. Os dadaístas empregaram particularmente o recurso da montagem, uma reunião de imagens "recicladas", mescladas com toda classe de tipos e ornamentos impressos nas composições dos textos. Suas habilidades para a propaganda, primeiramente utilizadas para a autopromoção, se dirigiram depois para a difusão do design como parte da revolução social na qual a liberdade - acreditavam - seria alcançada mediante $o$ incremento da mecanização.

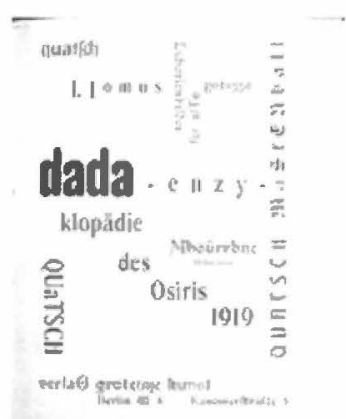

Figura 1- Exemplo de composição dadaista (www.dada.fr)

Para alguns historiadores do design gráfico, os avanços na área desde o Expressionismo até o Funcionalismo e do artesanato ao desenho para a produção em série industrial, podem ser traçados a partir de um desenho gráfico instável até o estabelecimento da Bauhaus, a célebre escola alemã estabelecida primeiramente em Weimar (Alemanha), em 1919.

No livro Diseño y comunicación - Teoría y enfoques críticos, Leonor Arfuch destaca a importância da escola Bauhaus no desenvolvimento do design e da imagem gráfica contemporâneos:

... não poderia faltar a referência à Bauhaus, momento de inflexão na constituição do campo disciplinar do desenho e da imagem gráfica e arquitetônica do moderno. 
Pese a que ela se constituiu através do aporte indistinto das vanguardas -sobretudo do Construtivismo, De stijl, do Abstracionismo e do Futurismo-, sua particular conformação e institucionalização a coloca num lugar a parte desse contexto. Sua inspiração racionalista, sua confiança no triunfo da técnica e em uma universalidade no acesso a um mundo sonhado como uma ordem da distribuição dos objetos, a própria noção configurativa do projeto a distanciam do gesto extremo da rebeldia vanguardista -da iconoclastia-para inscrevê-la na dinâmica das escolas, como realmente se configurou, em suas diferentes sedes e momentos histórico-políticos, a partir da legendária fundação em Weimar (1919), de seu trastado a Dessau em 1925, até a sua dissolução em Berlim, em 1933. sob ameaça do nazismo em ascensão. (Arfuch et al., 1997, p. 197)

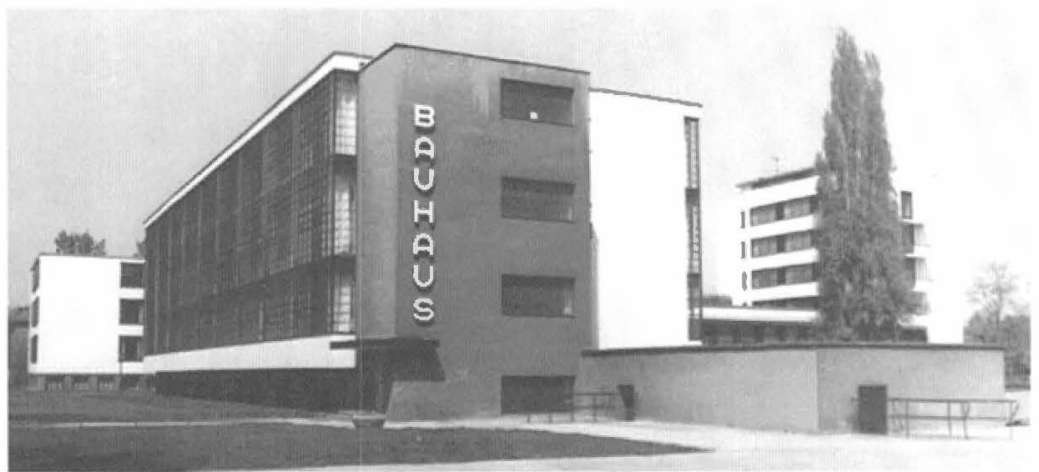

Figura 2 - Edificio sede da Bauhaus em Dessau (1925) - www.bauhausmuseum.de

As regras ditadas por esta escola chegaram a ser um estereótipo, identificado popularmente como a "tipografia da Bauhaus". Na verdade, as regras e os tipos eram peculiares, mas formavam parte de uma reforma muito mais radical que examinou os elementos do desenho gráfico e o papel que cada um deles jogava na hora de transmitir a informação.

Leonor Arfuch comenta também o ideal buscado pela escola na área da comunicação gráfica: 
Outra grande aspiração da Bauhaus esteve justamente no plano da comunicação gráfica, na conformação da sua especialidade como uma área moderna de incumbência, não equiparável às antigas artes gráficas. Ali intervieram não somente os legados vanguardistas, mas também os aportes técnicos e conceituais da psicologia, da publicidade e da propaganda de massas, gerando um espaço novo de articulação e de expressão, onde o projeto se abria não somente à inovação tipográfica e formal, mas também na inclusão da fotografia e outras composições plásticas. A utopia da ordem e do ideal de alcançar a democratização do acesso ao conhecimento e à distinção dos saberes, se plasmavan aqui em um primeiro passo fundamental: a legibilidade. (Arfuch et al, 1997, p. 200)

Na Bauhaus, a análise profunda da comunicação visual começou com um exame do alfabeto porque, na Alemanha o estilo predominante para a composição de textos era claramente arcaico, não pertencia à era industrial.

Os esforços realizados na Bauhaus resultaram na criação de novos tipos de letras desenhados com base geométrica estrita. A geometria fundamentou o funcionalismo, que buscava afastar-se do desenho artesanal com uma ênfase maior no racionalismo.

Em 1923, o pintor húngaro Lazlo Moholy-Nagy, que havia substituído a Johannes Itten como diretor do curso preliminar da Bauhaus, declarou que utilizava todos os tipos, de todos os tamanhos, formas geométricas, cores etc.

Philip Meggs salienta a importância do trabalho de MoholyNagy na evolução do ensino e da filosofia da Bauhaus:

A paixão de Moholy-Nagy pela tipografia e pela fotografia inspiraram a Bauhaus na área da comunicação visual e a conduziram na realização de experimentos importantes na unidade da tipografia e da fotografia. Moholy-Nagy via o desenho gráfico e especialmente o cartaz evoluir em direção à fototipografía. A uma integração objetiva da 
palavra e da imagem, para comunicar uma mensagem com independencia absoluta. Ele chamou isso de "nova literatura visual'. (Meggs, 1991, p. 365)

Moholy-Nagy havia chegado para ensinar, na Bauhaus, alguns meses antes da sua abertura ao público e realizou uma exposição onde mostrou seus experimentos gráficos. Este novo enfoque foi publicado posteriormente no livro Staatliches Bauhaus in Weimar 1919-1923.

Jan Tschichold, calígrafo e desenhista de livros, foi atraído pelo trabalho realizado na Bauhaus. Ele já havia sido professor da Academia de Leipzig, centro industrial da impressão e do livro na Alemanha na época, e se converteu no principal divulgador do movimento chamado posteriormente de Nova Tipografia (Neue Typographie), ao publicar em 1925 o trabalho Elementare Typographie, em uma edição especial do jornal Typographische Mitteilungen. Nele, entre outras observações sobre o uso da fotografia e a utilização de tipos sem serifas para preservar a legibilidade, Tschichold também reconheceu a importância das áreas não impressas nas páginas de uma publicação, a possibilidade de dispor linhas de tex to dispostas oblíqua ou verticalmente e a necessidade da adoção do padrão da indústria alemã (DIN) para a racionalização do uso do papel. Em 1928, Jan Tshichold desenvolveu e aperfeiçoou esse tema no livro de referência Die Neue Typographie (A nova tipografia).

Outro ativista da Nova Tipografia foi o dadaísta Kurt Schwitters. No seu jornal Merz, publicado em Hanover, o desenho das páginas obedecia aos preceitos da nova tipografia, com tipos sem serifa e espaços abertos na diagramação das páginas. Schwitters, tentou ainda reformular o alfabeto com um aporte revolucionário chamado de Systemscrifi, que apresentava letras ortofonéticas, com um sinal separado para cada som.

Kurt Schwitters foi um hábil organizador e propagandista de suas idéias. Mantinha correspondência com artistas e designers e dava cursos em várias localidades da Alemanha e em outros países da Europa. Esta atividade resultou na formação de um pequeno grupo, o Círulo de Novos Desenhistas de Publicidade (Ring 
Neuer Werbegestalter), composto por doze desenhistas de países distintos.

A primeira exposição dos trabalhos do grupo teve lugar na cidade de Colônia (no Kunstgewerbemuseum), em março de 1928. Outros eventos se seguiram a esse e neles os membros do Ring Nener Werbegestalter buscavam esclarecer a nova técnica de desenho visual.

Em 1927, o historiador de arte Walter Dexel escreveu um artigo no jornal Frankfurter Zeitung sob título "O que é a Nova Tipografia?". O conteúdo trazia uma explicação bastante simples da linha adotada na Bauhaus por Moholy-Nagy, mas Dexel criticava alguns dos rebuscamentos adotados, particularmente no uso de normas que interferiam com a legibilidade. Ele defendia também uma aplicação cada vez mais normalizada dos tipos sem serifa e propunha que fossem utilizadas somente letras maiúsculas na composição dos textos.

Nesta mesma época, outro designer de Frankfurt, Willi Baumeister, já avalizava a tese de que o desenho dos tipos gráficos devia respeitar o movimento do olho e, por isso, o arranjo simétrico estático era impróprio à legibilidade. Lazlo Moholy-Nagy enfatizou este argumento, quando observou que a nova tipografia devia expressar a comunicação na sua forma mais intensiva e buscar a claridade absoluta.

Em 1926, o pintor Max Burchartz, que havia mantido contato estreito com os experimentos gráficos da Bauhaus, estabeleceu uma agência de publicidade em Werbebau, na região do Ruhr (Alemanha). Num artigo para a revista Form (Forma), Burchartz mostrou suas idéias sobre a efetividade da publicidade, introduzindo o conceito moderno de mensagem e receptor. Para ele a expressividade das peças gráficas deveria derivar-se da organização do material bruto e da compensação dos contrastes (as oposições, a tensão, o conflito).

Os princípios de Burchartz se realizaram nos desenhos que estabeleceram o estilo do Modernismo Internacional, que sobreviveu ao nazismo e depois ressurgiu como o "Estilo Suíço".

Em 19290 interesse crescente pela fotografia se refletirá na exposição Film und Foto, em Werkbund (Alemanha), onde em uma 
das salas John Heartfield se arrisca com combinações tipográficas mescladas com fotografias partindo das suas obras dadaístas, desenvolvidas após o término da Primeira Guerra Mundial. Hartfield expõe colagens fotográficas, ocultando as montagens com um retoque cuidadoso.

Os trabalhos de Heartfield e de outros jovens pioneiros da Nova Tipografia aparecerão em publicações da indústria gráfica e também na lendária revista de publicidade alemã Gebrauchsgraphik (Aplicação Gráfica).

O designer Herbert Bayer, que havia organizado o departamento de publicidade e impressão da Bauhaus, foi também responsável pelo desenvolvimento da papelaria e do padrão de papéis da gráfica da escola. Por isto, o material gráfico impresso na Bauhaus em 1925 apresentava um modelo austero, com marcada utilização na diagramação de blocos verticais e horizontais e uso do vermelho e do negro. Isto identificava o "Desenho Bauhaus", ainda que estes elementos fossem comuns a muitos vanguardistas, como o russo Lissitzky que, naquele momento, estava trabalhando em Berlim, e também a Kurt Schwitters que estava em Hanover. Mas, apesar da sobriedade dessa técnica, ela se apresentava bastante clara e efetiva para a comunicação.

Bayer, que utilizava o método geométrico construtivista para organizar as relações na folha de papel impresso, passou depois a utilizar ilustrações menos dinâmicas e tipos serifados, especialmente os neoclássicos Bodoni. Esta mudança marcou seu novo interesse pelas "leis da psicologia e fisiologia", que já sugeria uma nova linguagem da publicidade.

\section{abcdeffgGhijkkImno pqrstruvwXyz ßœe E6 1234567890}

Figura 3 - Exemplo de familia tipográfica desenvolvida por Bayer www.bauhausmuseum.de)

Em 1933, o novo desenho funcional havia sido aceito na Alemanha e seu ensino foi introduzido nas escolas através de Willi 
Baumeister (Frankfurt), Max Burchartz (Essen), Walter Dexel (Magdeburg) e Trump (Berlim). No entanto, quando os nazistas chegaram ao poder, muitos dos designers progressistas perderam seus trabalhos e a Bauhaus foi fechada.

Philip Meggs comenta as circunstâncias da dissolução da Bauhaus:

A nuvem crescente da perseguição nazista levou a muitos professores da Bauhaus a unir-se aos artistas e intelectuais que fugiram para os Estados Unidos. Em 1937. Gropius y Marcel Breuer estavam dando aulas de arquitetura na Universidade de Harvard e Moholy-Nagy estabeleceu a Nova Bauhaus (agora o Instituto de Desenho) em Chicago. Um ano mais tarde, Herbert Bayer iniciou a fase norte-americana de sua carreira como designer. Este êxodo pelo Atlântico iria causar um impacto significativo no desenho norte-americano depois da Segunda Guerra Mundial. (Meggs,1991, p. 373)

Na verdade, os conservadores sempre haviam sido inimigos das inovações da Nova Tipografia. Os nazistas classificaram o movimento como comunismo cultural e parodiaram seus cartazes em exposições de Arte Degenerada (Entartete Kunst).

Os desenhistas alemães exilados levaram sua experiência no desenho gráfico a outros países. Na Suíçà, se uniram a uma tradição já existente. Schawinski continuou sua carreira na Itália até que, em 1936, teve que ir a Nova Iorque por causa da perseguição do fascismo.

Desde o final do Século XIX a Suíça contribuiu para os avanços do desenho gráfico na Europa. Alguns dos cartazes realizados por artistas suíços na época já adiantavam alguns aspectos do futuro desenvolvimento do "Estilo Suíço".

Nas primeiras décadas do Século XX as técnicas publicitárias norte-americanas tiveram influência na criação gráfica da Europa, incluindo a Suíça. Este acontecimento se refletiu particularmente no uso do slogan ou título que proporcionava uma comunicação direta e efetiva. 
Porém, os Estados Unidos também admiravam a elegância do desenho europeu. O suíço Herbert Matter, um dos inovadores do desenho gráfico no período que precedeu a Segunda Guerra Mundial, obteve um grande reconhecimento dos seus trabalhos na América.

Matter foi um destacado pintor que estudou em Genebra e Paris, onde experimentou técnicas inovadoras de colagem e montagem de anúncios e cartazes publicitários.

Em 1931, Matter voltou a Suiça com uma compreensão maior das possibilidades imaginativas da fotografia e do processo de impressão de imagens fotográficas. Suas montagens, com cores vermelho, azul e negro, eram quase surrealistas. Matter empregou esta técnica em cartazes e prospectos turísticos, mesclando fotografias recortadas em montagens cuidadosas.

A influência do movimento vanguardista foi notável também na publicidade dos produtos da engenharia elétrica, química e da indústria de construção suíças. Em 1929, o designer Anton Stankowski chegou a Zurique, depois de ter trabalhado em Ruhr (Alemanha), e estreou o desenho gráfico aplicado à difusão dos produtos industriais na Suíça.

Os trabalhos gráficos de Stankowski apresentavam os produtos de forma direta e clara, com a informação essencial disposta assimetricamente em um espaço livremente organizado.

O designer alemão Jan Tschichold, que havia promovido o uso da fotografia, buscou refúgio na Suíça em 1933 e em 1938 produziu na Basiléia o último grande trabalho que segue os preceitos da tipografia assimétrica para a exposição "Der Berufsphotograph" (O fotógrafo profissional).

Herbert Matter y Tschichold dominavam os processos utilizados na indústria da impressão e isto possibilitou que outros expressivos designers suíços também obtivessem essas informações. Seus experimentos com impressões superpostas não serviram somente para criar efeitos de profundidade, mas permitiram que as imagens em cores diferentes se apresentassem no mesmo espaço sem anular-se umas as outras. O efeito obtido modulava o sentido das imagens e reforçava as combinações entre elas mesmas e a conjugação com o tex to impresso. 
Outro importante inovador gráfico suíço foi Max Bill, um pintor, escultor, arquiteto, desenhista industrial e teórico do desenho gráfico que havia voltado a Zurique em 1929, depois de dois anos na Escola Bauhaus de Dessau. Ele trabalhou na Suíça em publicidade como desenhista de anúncios, dominando rapidamente as técnicas de impressão.

Entre todos os trabalhos de Max Bill, os cartazes são sua mais importante contribuição ao desenvolvimento do desenho gráfico. Porém, sua variada produção de catálogos técnicos, marcas registradas, papelaria, jornais políticos, capas e anúncios são admiráveis. Seu êxito mais importante nos anos 30 foi o projeto do pavilhão suíço para a Exposição de Milão (1936). A austeridade controlada da proposta proporcionou um cenário perfeito para o formalismo radical dos cartazes expostos. Esta foi a primeira manifestação internacional do "Estilo Suíço" que, vinte cinco anos depois, influiu, de forma dominante, o desenho gráfico em todo o mundo.

A Suíça retornou fortemente ao Modernismo nos anos que se seguiram à Segunda Guerra Mundial. Na Basiléia, os estudantes da Escola de Artes e Ofícios (Algemeine Gewerbeschule) reeditaram os trabalhos mais importantes dos teóricos dos anos 20, como os da Escola Bauhaus, apesar do rechaço de Emil Ruder, professor da mesma Gewerbeschule, que já os considerava obsoletos.

Ruder defendia o desenho total sistemático e a utilização de uma estrutura com um arranjo complexo para harmonizar, uns com os outros, toda a variedade de elementos gráficos.

Max Bill pensava que o regresso aos métodos chamados efetivos em desenho estava relacionado simplesmente com o fato que estes haviam sobrevivido no tempo.

Em 1955, o pintor suíço pós-construtivista Karl Gerstner defendeu na revista Werk -especializada em arquitetura e desenho- que o desenho gráfico não tinha nada a mostrar à arte, mas que poderia beneficiar-se seguramente da rigorosa disciplina da arte concreta.

Em 1957, Gerstner desenhou para seu colega Markus Kutter - libro Schiff nach Europa, onde a superfície das páginas se estruturava em uma rede de quadrados que ele chamou de "tela flexível em que a imagem tipográfica se acomoda, com uma quase 
ilimitada liberdade de expressão". No livro, além da narrativa tradicional, Karl Gestner buscou enfatizar o conteúdo ao utilizar estilos empregados nos jornais, na publicidade e nos roteiros cinematográficos.

Para escrever sobre publicidade na revista Werk, Gerstner convidou Siegfried Odermatt, um designer com vários anos de experiência em agências de publicidade de Zurique (Suíça) que havia trabalhado livremente com as idéias de Stankowski y Cyliax, os pioneiros da nova publicidade nos anos 30 .

O trabalho de Odermatt, que combinava a apresentação limpa e eficiente da informação com uma qualidade visual dinâmica, enfatizava a distância entre as idéias de publicidade praticadas em Nova Iorque e o que se fazia em Zurique. Talvez a diferença mais evidente era que os publicitários suíços olhavam seu trabalho como designers e não como diretores de arte.

Os suíços raramente utilizavam um título único, o tipo maior era o nome do produto, a imagem principal derivava diretamente do produto, não como uma ilustração para um conceito de Marketing.

Na revista Werk, Odermatt descreveu os quatro princípios que a publicidade deveria seguir: 1. Conseguir a atenção; 2. Apresentar clara e objetivamente o produto, serviço ou idéia; 3. Apelar aos instintos do consumidor; 4. Fixar na memória. (Hollis,1996, p. 131).

A difusão internacional do "Estilo Suíço" se deveu principalmente a Graphis, uma revista mensal publicada em Zurique depois da Segunda Guerra Mundial, que compaginou a reprodução e a discussão da arte comercial estrangeira com revisões das artes gráficas. Esta revista foi responsável também pela publicação de livros com temas históricos da área.

Mas a influência mais específica veio do jornal Neue Grafik. Lançada em 1959, esta publicação trilingüe já refletia na sua apresentação gráfica refinada os avanços do design suíço e se caracterizará por mostrar a filosofia do movimento à comunidade internacional.

Josef Müller-Brockmann, um dos editores do Neue Grafik, foi também o mais famoso dos teóricos e profissionais da nova corrente do grafismo suiço, durante as décadas de 1950 e 1960. Ainda hoje seus trabalhos mantém um frescor contemporâneo, como se 
tivessem sido criados ontem, comunicando suas mensagens com claridade e intensidade.

Müller-Brockmann defendeu uma expressão gráfica universal que se apresentasse com objetividade ao público, livre da intromissão dos sentimentos subjetivos do designer e despojada das técnicas de persuasão utilizadas pela publicidade.

O Estilo Tipográfico Internacional, como ficou conhecido depois o movimento suíço, apurou os desejos alimentados desde antes da Segunda Guerra Mundial na exploração da objetividade da comunicação visual e na internacionalização da nova profissão de designer gráfico. Colaborou também no desenvolvimento de uma linguagem tipográfica mais adequada aos avanços que a comunicação experimentou desde a segunda metade do Século XX.

Para Anna Calvera, a importância do grafismo suíço para o desenho gráfico contemporâneo radica em:

(...) seu peculiar modo de entender a finalidade ao mesmo tempo que pressupunha uma opção de tipo comunicativo: a decisão de informar mais do que convencer, de mostrar mais que provocar, de dizer mais do que sugerir. (...) Provavelmente por este motivo os desenhistas gráficos suiços conseguiram representar visualmente as noções conceitualmente mais abstratas -como a velocidade e não o automóvel, a energia e a seriedade e não o dinheiro. (...) A importância histórica do grafismo suíço depende ainda de outro fator. Foi o intento mais rigoroso e sistemático acontecimento na história do desenho gráfico para definir sua especialidade como profissão e alcançar o reconhecimento da sua autonomia como atividade. Uma autonomia que se estabelece tanto com relação à tradição das artes gráficas como aos subsidios das artes plásticas e que se sustentam sobre a base da função social específica do desenho em uma economia de mercado, como a dos países ocidentais na fase histórica que as vezes se chama neo-capitalismo avançado e em outras, sociedade da abundância. (Müller- Brockmann,1986, p. 08) 


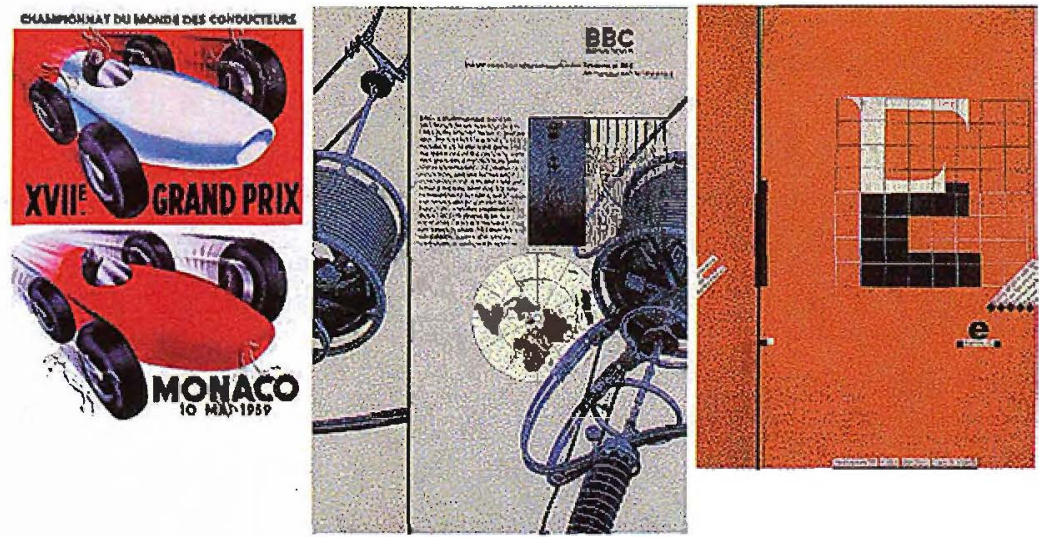

Figuras 4, 5 e 6 Exemplos de cartazes no estilo sulço (www.internationalposters.com)

Nos anos 70 e 80, uma nova geração de designers se uniu com antigos profissionais para adaptar nos seus métodos cada trabalho, sem limitar-se à utilização dos tipos gráficos característicos do movimento e aos traçados retilíneos que personificavam o estilo suíço.

\section{Bibliografia}

ARFUCH, L.; CHAVES, N.;LEDESMA, M. 1997. Diseño y comunicación - teoría y enfoques críticos. Buenos Aires: Ed. Paidós.

CRAIG, J., BARTON, B. 1987. Thirty Centuries of Graphic Design. Nueva York: Watson-Guptill Publications.

HOLLIS, R. 1996. Graphic Design - a concise history. Londres: Thames and Hudson Ltd, 1996.

MEGGS, P. B. 1991. Historia del diseño gráfico. México: Editorial Trillas.

MÜLLER-BROCKMANN, J. 1986. Historia de la comunicación visual. Barcelona: Editorial Gustavo Gilli.

SPENCER, H. 1995. Pioneros de la tipografia moderna. Barcelona: Ediciones Gustavo Gili. 